\title{
HEAVY EYE SYNDROME
}

\author{
H. R. Padmini, Prachi Subhedar
}

1. Professor \& HOD. Department of Ophthalmology, Adichunchanagiri Institute of Medical Sciences.

2. Post Graduate. Department of Ophthalmology, Adichunchanagiri Institute of Medical Sciences.

\section{CORRESPONDING AUTHOR:}

Dr. H.R. Padmini

Adichunchanagiri Institute of Medical Sciences,

Mandya, Karnataka.

E-mail: prachi.subhedar@gmail.com

Heavy eye syndrome is an association of anisometropia, usually with high myopia, and hypophoria or hypotropia. The more myopic eye is hypotropic. This disorder was called heavy eye syndrome on the basis of the fanciful idea that the larger, more myopic eye is in a relatively low position, as though it were too heavy. Of course, gravity has no discernible role in the causation, which appears to be an abnormally low muscle path of the lateral rectus in the involved eye. It is caused by conversion of lateral rectus muscle function from abduction to infraduction leading to impaired abduction and supraduction.

In the usual clinical situation, anisomyopia or unilateral high myopia exists, in the range $2-20 \mathrm{D}$. The vertical deviation ranges from 2 to 25D, although there is no association between the amount of anisometropia and the amount of hypotropia. Elevation of the low eye may be limited. Frequently, the head tilts to the side of the hypotropic eye, which may be compensatory to achieve single vision by the creation of a base-up prism effect before the hypotropic eye.

Here we present a 25 year old female patient, who presented with outward and downward turning of right eye gradually progressing since childhood. Her visual acuity was counting finger $1 \mathrm{~m}$ in the right eye and left eye visual acuity was counting finger $5 \mathrm{~m}$ correctable to 6/9. The cover test revealed a marked exodeviation with right hypodeviation. On prism bar cover test there was -55 PD of exodeviation and 4 PD of hypodeviation of the RE with marked amblyopia with central fixation. LE visual acuity was counting finger $4 \mathrm{~m}$ improving upto 6/12 with correction. High myopic degenerative changes were seen in both the eyes on fundoscopy. Refraction in RE was -20 D improving upto 6/60 and LE -7D improving upto 6/9. Binocularly the patient complained of diplopia because of high anisometropia, hence surgery was indicated for cosmetic as well to improve the fixation and thereby improving the vision with contact lens in both the eyes. MRI revealed lateral rectus displacement inferiorly and the superior rectus is shifted nasally. Forced duction test preoperatively showed restriction in adduction and supraduction in both cases.

An $8 \mathrm{~mm}$ recession of the right lateral rectus muscle with $2 \mathrm{~mm}$ upward shifting of lateral rectus insertion and medial rectus resection of $7 \mathrm{~mm}$ was performed. Post operatively the patient had orthophoria in the primary position and visual improvement achieved by soft contact lens

COMMENT: High axial myopia, acquired large angle strabismus, limited movements of the eye and displacement of the lateral and superior rectus muscles. According to a large study the condition may be due to abnormal rectus muscle anatomy, axial elongation and alteration in the direction of the lateral and superior recti, mitochondrial myopathy, orbital connective tissue degeneration associated with aging. High myopia should be considered in the differential 
diagnosis such as the $6^{\text {th }}$ nerve palsy excluded by Positive forced duction test, Thyroid eye disease excluded by Normal muscles on CT, Myasthenia Gravis excluded by a Normal tensilon test. Surgery is indicated for visual rehabilitation and for cosmesis. Several surgical techniques are used such as the Yokoyama procedure (loop myopexy), hemi transposition of rectus muscle, and partial Jensen's technique which is relatively simple and safe.

In conclusion, patients with strabismus fixus should be evaluated by CT. If the deviant paths of the LR and SR muscles are demonstrated, the surgical methods described would be a surgical option.

\section{REFERENCES:}

1. Von Noorden GK, Campos EC, Binocular Vision and Ocular Motility: Theory and Management of Strabismus. St. Louis: CV Mosby Co.; 2002, pp. 405,473-474.

2. Ruter T, Demer JL. Heavy eye syndrome in the absence of high myopia: a connective tissue degeneration in elderly strabismus patients. J AAPOS 2009. [Epub ahead of print]

3. Ejzenbaum F, Goldchmit M, Souza-Dias CR. Surgical correction of progressive high myopic esotropia by Yamada's technique: report of two cases. Arq Bras Oftalmol 2005;68:547-550.

4. Rowe FJ, Noonan CP. Surqical treatmeat for progressive esotropia in the setting of highaxial myopia. J AAPOS 2006;10:596-597.

5. Larsen PC, Gole GA. Partial Jensen's procedure for the treatment of myopic strabismus fixus. J AAPOS 2004:8:393-395.

6. Bagheri A, Adhami F, Repka MX. Bilateral recession-resection surgery for convergent strabismus fixus associated with high myopia. Strabismus 2001;9:225-230.

7. Krzizok TH, Kaufmann H, Traupe H. New approach in strabismus surgery in high myopia. Br J Ophthalmol 1997;81:625-630

8. Tanaka A, Ohno-Matsui K, Shimada N, Hayashi K, Shibata Y, Yoshida T, Yamashita M, Tokoro T, Mochizuki M: Prevalence of strabismus in patients with pathologic myopia. J Med Dent Sci 2010; 57:75-82.

\section{CASE REPORT:}
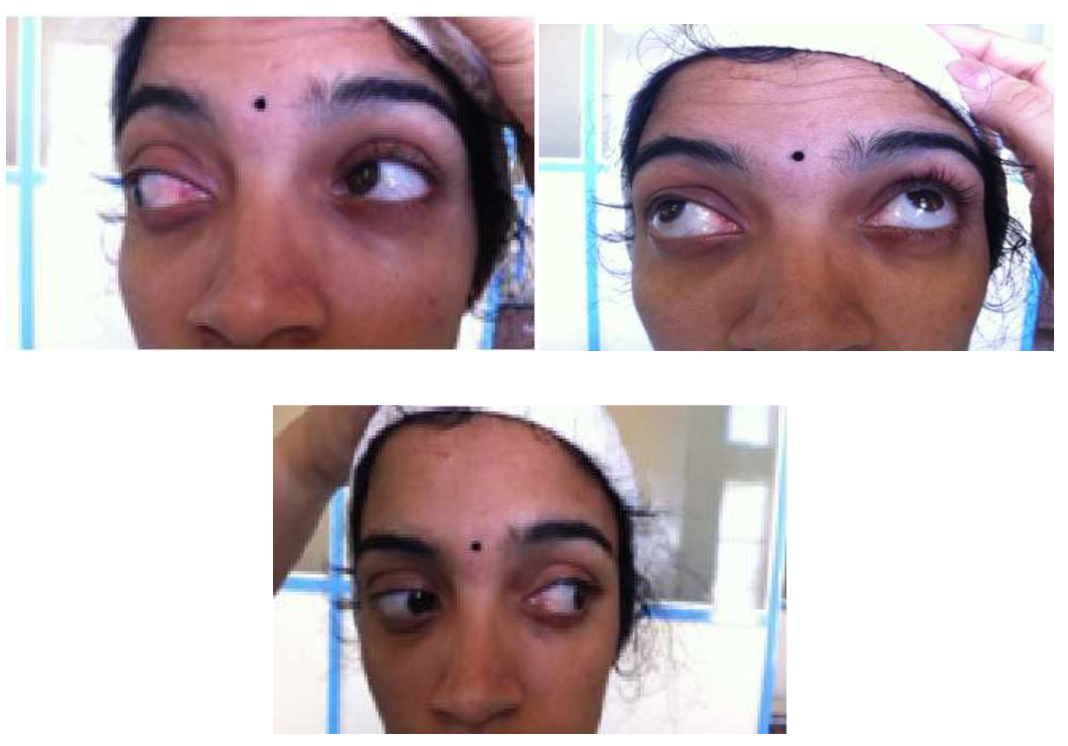


\section{CASE REPORT}
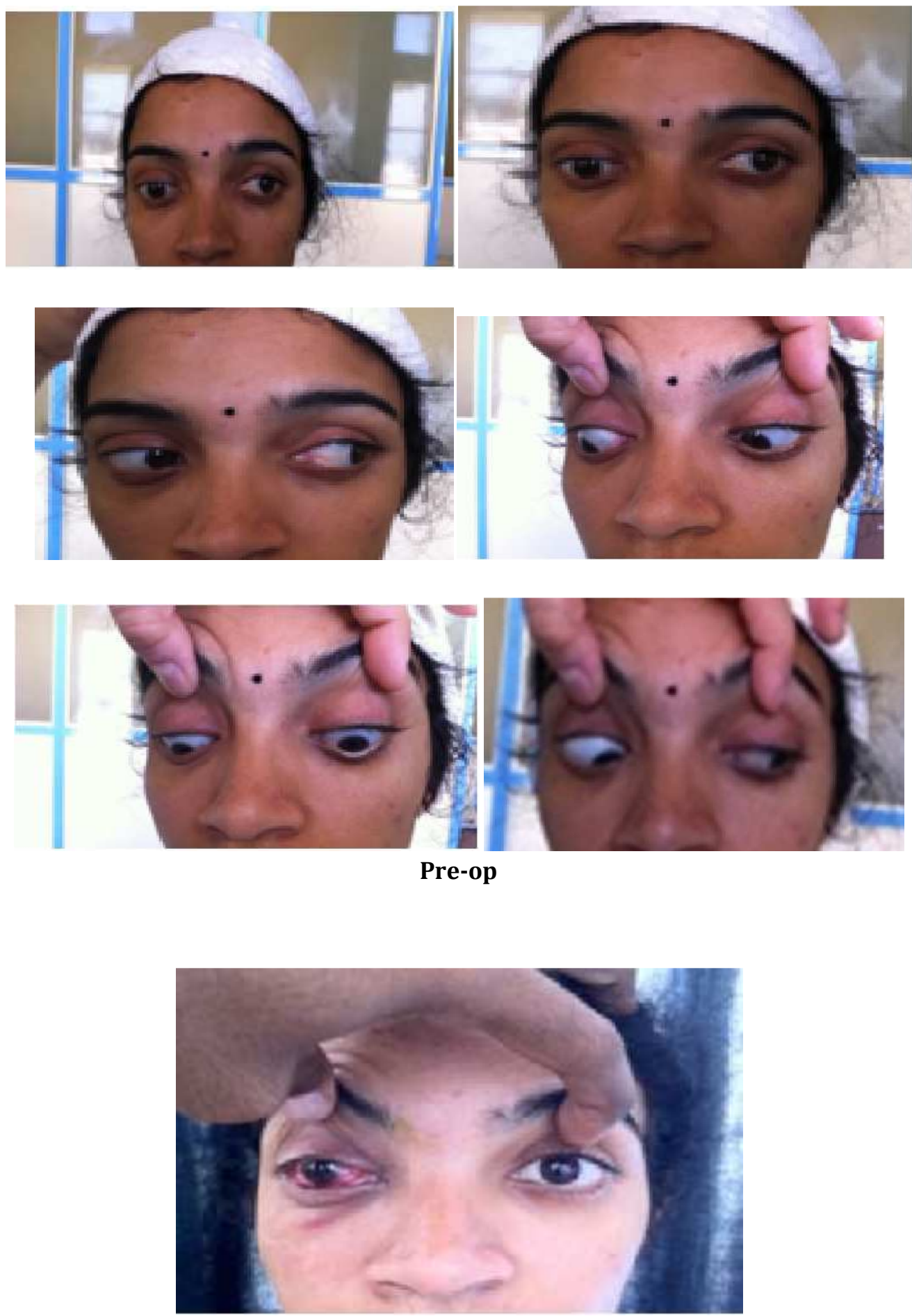

Post-op 


\section{CASE REPORT}
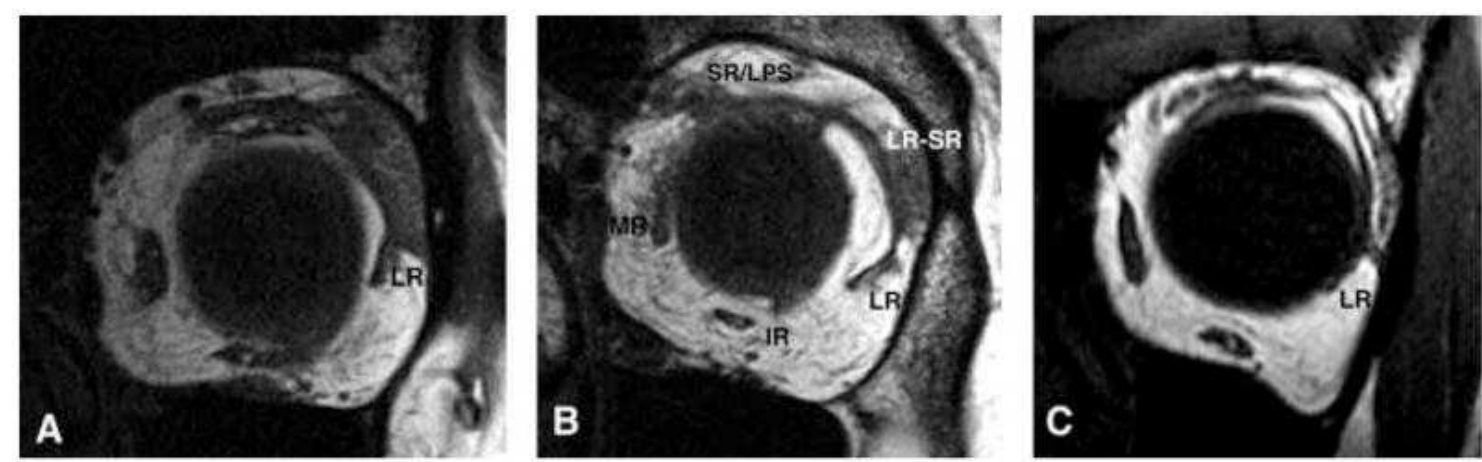

MRI - Showing LR displacement inferiorly and slight SR nasal shift. 